\title{
The NA 1.7 blocker protoxin II reduces burn injury-induced spinal nociceptive processing
}

\author{
Jose Vicente Torres-Pérez ${ }^{1}$ - Pavel Adamek ${ }^{2,3}$ • Jiri Palecek ${ }^{2}$ • Marcela Vizcaychipi ${ }^{4}$. \\ Istvan Nagy ${ }^{1}$ (D) Angelika Varga $^{5}$
}

Received: 6 June 2017 / Revised: 7 September 2017 / Accepted: 2 October 2017 / Published online: 23 October 2017

(C) The Author(s) 2017. This article is an open access publication

\begin{abstract}
Controlling pain in burn-injured patients poses a major clinical challenge. Recent findings suggest that reducing the activity of the voltage-gated sodium channel $\mathrm{Na}_{\mathrm{v}} 1.7$ in primary sensory neurons could provide improved pain control in burn-injured patients. Here, we report that partial thickness scalding-type burn injury on the rat paw upregulates $\mathrm{Na}_{\mathrm{v}} 1.7$ expression in primary sensory neurons $3 \mathrm{~h}$ following injury. The injury also induces upregulation in phosphorylated cyclic adenosine monophosphate response element-binding protein (p-CREB), a marker for nociceptive activation in primary sensory neurons. The upregulation in p-CREB occurs mainly in $\mathrm{Na}_{\mathrm{v}} 1.7$-immunopositive neurons and exhibits a peak at $5 \mathrm{~min}$ and, following a decline at $30 \mathrm{~min}$, a gradual increase from $1 \mathrm{~h}$ post-injury. The $\mathrm{Na}_{\mathrm{v}} 1.7$ blocker protoxin II (ProTxII) or
\end{abstract}

Electronic supplementary material The online version of this article (https://doi.org/10.1007/s00109-017-1599-0) contains supplementary material, which is available to authorized users.

Istvan Nagy

i.nagy@imperial.ac.uk

1 Nociception Group, Section of Anaesthetics, Pain Medicine and Intensive Care, Department of Surgery and Cancer, Imperial College London, Chelsea and Westminster Hospital, 369 Fulham Road, London SW10 9NH, UK

2 Department of Functional Morphology, Institute of Physiology, The Czech Academy of Sciences, Prague, Czech Republic

3 Department of Physiology, Faculty of Science, Charles University, Prague, Czech Republic

4 Department of Anaesthetics, Chelsea and Westminster Hospital NHS Trust, 369 Fulham Road, London SW10 9NH, UK

5 MTA-DE-NAP B-Pain Control Research Group, Department of Anatomy, Histology and Embryology, University of Debrecen, Debrecen 4012, Hungary morphine injected intraperitoneally $15 \mathrm{~min}$ before or after the injury significantly reduces burn injury-induced spinal upregulation in phosphorylated serine 10 in histone $\mathrm{H} 3$ and phosphorylated extracellular signal-regulated kinase 1/2, which are both markers for spinal nociceptive processing. Further, ProTxII significantly reduces the frequency of spontaneous excitatory post-synaptic currents in spinal dorsal horn neurons following burn injury. Together, these findings indicate that using $\mathrm{Na}_{\mathrm{v}} 1.7$ blockers should be considered to control pain in burn injury.

\section{Key messages}

- Burn injury upregulates $\mathrm{Na}_{\mathrm{v}} 1.7$ expression in primary sensory neurons.

- Burn injury results in increased activity of $\mathrm{Na}_{\mathrm{v}} 1.7$-expressing primary sensory neurons.

- Inhibiting $\mathrm{Na}_{\mathrm{v}} 1.7$ by protoxin II reduces spinal nociceptive processing.

- $\mathrm{Na}_{\mathrm{v}} 1.7$ represents a potential target to reduce pain in burn injury.

Keywords Pain $\cdot \mathrm{p}$-ERK1/2 $\cdot$ Primary sensory neuron $\mathrm{p}-\mathrm{S} 10 \mathrm{H} 3 \cdot$ Spinal cord

Burn injury is associated with moderate to severe pain that represents a significant clinical challenge [1]. The lack of effective pain management in burn-injured patients can lead to longterm consequences including the development of anxiety, depression, post-traumatic stress disorder and chronic pain [1]. Therefore, there is a need for the development of novel analgesic approaches to control pain in burn-injured patients.

A series of mediators produced and released during inflammation that ensues after burn injury activate a major sub-set of primary sensory neurons $[1,2]$. The resulting generation and 
propagation of action potentials initiate nociceptive processing in the central nervous system and lead to the experience of pain. Voltage-gated $\mathrm{Na}^{+}$channels $\left(\mathrm{Na}_{\mathrm{v}}\right)$, distinguished by their alpha sub-units [3-5], are pivotal for the generation and propagation of action potentials in neurons [6]. Recent studies identified $\mathrm{Na}_{\mathrm{v}} 1.7$ as a putative key molecule for the development of heat hypersensitivity in burn injury $[4,7,8]$. Therefore, in the present work, we examined whether specific blockade of $\mathrm{Na}_{\mathrm{v}} 1.7$ with the selective toxin, protoxin II (ProTxII) $[9,10]$, is a feasible target to reduce nociceptive processing in burn injury.

\section{Materials and methods}

\section{Animals, burn injury and treatment}

We obeyed the UK Animals (Scientific Procedures) Act 1986, the guidelines of the revised National Institutes of Health Guide for the Care and Use of Laboratory Animals, Directive 2010/63/EU of the European Parliament and of the Council on the Protection of Animals Used for Scientific Purposes and the Committee for Research and Ethical Issues of IASP published in Pain, 16 (1983) 109-110 and adhered to Good Laboratory Practice and ARRIVE guidelines. Procedures were approved by veterinary services at all relevant institutions. Every effort was made to minimise the number of animals used and the potential distress. Animals were housed in climate-controlled rooms, on a $12 \mathrm{~h} \mathrm{light/dark}$ cycle, with food and water ad libitum. In total, 36 male Sprague-Dawley rats (150-200 g), 5 male Wistar rats (P21), 2 wild-type (WT, $\sim 22 \mathrm{~g}$ ) mice and 2 mice lacking $\mathrm{Na}_{\mathrm{v}} 1.7$ in Nav1.8-expressing cells (Nav1.7cKO, $22 \mathrm{~g}$; [5]; both types on C57BL/6 background) were used.

Burn or sham injury was induced as described previously $[11,12]$. Briefly, animals were anaesthetised by intraperitoneal urethane $(0.02 \mathrm{mg} / \mathrm{g})$ or isoflurane $(3 \%$, for spinal cord slice preparation) and one of the hind paws (both paws for spinal cord slices) was immersed into 60 or $37^{\circ} \mathrm{C}$ water up to the knee for $2 \mathrm{~min}$. Anaesthesia was maintained for up to 180 min post-injury. Following intraperitoneal sodium pentobarbital, animals were either transcardially perfused with saline then 4\% paraformaldehyde or the L4-L5 dorsal root ganglia (DRGs) were dissected from both the ipsilateral and contralateral sides. ProTxII $(0.1 \mathrm{mg} / \mathrm{kg}$; Tocris $)$ or morphine ( $3 \mathrm{mg} / \mathrm{kg}$; Sigma) was injected intraperitoneally $15 \mathrm{~min}$ before or after the injury.

\section{Western blotting}

The protocol included tissue homogenisation with a pestle and mortar in ice-cold RIPA buffer (Amresco) and protease inhibitor cocktail (Sigma-Aldrich), sonication for $1 \mathrm{~h}$ at $4{ }^{\circ} \mathrm{C}$, spinning for $30 \mathrm{~min}$ at $14,000 \mathrm{rpm}$ at $4{ }^{\circ} \mathrm{C}$ and denaturing at $95{ }^{\circ} \mathrm{C}$ for $5 \mathrm{~min}$. NuPAGE Novex $4-12 \%$ Bis-Tris protein gels (Invitrogen, UK) were used for separation. After transfer to PVDF membranes (Invitrogen, UK), samples were incubated in 5\% non-fat milk powder (Sigma, UK) for $1 \mathrm{~h}$ at room temperature, then in anti- $\mathrm{Na}_{\mathrm{v}} 1.7$ and anti- $\beta$-tubulin III antibodies at $4{ }^{\circ} \mathrm{C}$ overnight followed by incubation in secondary antibodies at room temperature for $1 \mathrm{~h}$ and visualisation with the Luminol kit (Santa Cruz, USA; Supplementary Table 2). Membranes were examined in a G:Box (SynGene, UK) using the GeneSnap software package (Synoptics Ltd, SynGene). Analysis was done by ImageJ; $\mathrm{Na}_{\mathrm{v}} 1.7$ intensities were normalised to $\beta$-tubulin intensities in each of the 16 samples (samples from the ipsilateral and contralateral sides of 8 animals). Then, the ratio of the normalised intensities found on the ipsilateral and contralateral sides in each animal was calculated and averaged.

\section{Immunolabelling}

The L4-L5 segments of the spinal cord and the L4 and L5 DRGs were dissected, post-fixed overnight in $4 \%$ paraformaldehyde and cryoprotected in $30 \%$ sucrose. Tenmicrometre sections were cut and incubated in PBS containing $0.3 \%$ Triton-X 100 (PBST) for $10 \mathrm{~min}$, then in $10 \%$ normal donkey serum (NDS) for $1 \mathrm{~h}$ followed by the primary antibody (Supplementary Table 1). For visualisation of the phosphorylated serine 10 in histone H3 (p$\mathrm{S} 10 \mathrm{H} 3)$ staining, the tyramide signal amplification procedure was used [12]. Other immunoreactions were visualised by Alexa Fluor-conjugated secondary antibodies (Supplementary Table 1). Slides were coverslipped with Vectashield (Vector Laboratories, UK) and examined with a Leica microscope attached to a Hamamatsu colourchilled 3CCD camera.

\section{In vitro electrophysiology}

The spinal cord slices were prepared using sham-injured and burn-injured Wistar rats as described previously [13]. One hour after the injury, 300- $\mu \mathrm{m}$ transverse slices were cut and incubated in dissection solution ((in mM) $95 \mathrm{NaCl}, 1.8 \mathrm{KCl}, 7$ $\mathrm{MgSO}_{4}, 0.5 \mathrm{CaCl}_{2}, 1.2 \mathrm{KH}_{2} \mathrm{PO}_{4}, 26 \mathrm{NaHCO}_{3}, 25$ D-glucose and 50 sucrose) for $30 \mathrm{~min}$ at $35{ }^{\circ} \mathrm{C}$, stored in a recording solution ((in mM) $127 \mathrm{NaCl}, 1.8 \mathrm{KCl}, 1.2 \mathrm{KH}_{2} \mathrm{PO}_{4}, 2.4$ $\mathrm{CaCl}_{2}, 1.3 \mathrm{MgSO}_{4}, 26 \mathrm{NaHCO}_{3}$ and $25 \mathrm{D}$-glucose) at room temperature $\left(21-24^{\circ} \mathrm{C}\right)$ and allowed to recover for at least $1 \mathrm{~h}$ before recordings. All extracellular solutions were saturated with carbogen $\left(95 \% \mathrm{O}_{2}, 5 \% \mathrm{CO}_{2}\right)$. 
Whole-cell patch-clamp recordings (at $21-24^{\circ} \mathrm{C}$ ) were performed from the superficial dorsal horn neurons clamped at $-70 \mathrm{mV}$ in the presence of $10 \mu \mathrm{M}$ bicuculline and $5 \mu \mathrm{M}$ strychnine in the bath solution as described previously [13]. The intracellular pipette solution contained (in $\mathrm{mM}$ ) 125 gluconic acid lactone, $15 \mathrm{CsCl}, 10$ EGTA, 10 HEPES, 1 $\mathrm{CaCl}_{2}, 2 \mathrm{Mg}_{2} \mathrm{ATP}$ and $0.5 \mathrm{NaGTP}$ and was adjusted to pH 7.2 with $\mathrm{CsOH}$. An Axopatch 1D (Axon Instruments, USA) amplifier, a Digidata 1440A digitizer (Molecular Devices, USA) and the pCLAMP 10.5 software package were used for recordings. Low-pass filter $(2 \mathrm{kHz}), 10-\mathrm{kHz}$ sampling rate and $80 \%$ series resistance compensation were used. Spontaneous excitatory post-synaptic currents (sEPSCs) with an amplitude of $5 \mathrm{pA}$ or greater (at least twice of the noise) were included in the frequency and amplitude analyses. Basal activity recording was followed by recoding in the presence of ProTxII (10 nM in $0.1 \%$ BSA, Tocris) for $5 \mathrm{~min}$. In the end of the recording protocol, capsaicin $(200 \mathrm{nM})$ was applied to find whether the neuron received nociceptive input.

\section{Statistical analysis}

Data were analysed as previously reported [12]. In brief, power calculations were used to estimate sufficient sample size using an online-based software (http://homepage.stat.uiowa. edu/ rlenth/Power/) and statistical analyses were carried out using the SPSS program (IBM SPSS statistics 22.0 for Windows). Data from immunostaining were analysed using a generalised linear model (GzLM), with significance assessed with the Wald chi-squared test. For Western blotting, independent $t$ tests were used. In all cases, differences were regarded significant at $p<0.05$. The statistical significance of ProTxII on sEPSCs was tested using paired $t$ test and $t$ test with Bonferroni correction for multiple comparisons. The sEPSC frequency after ProTxII application was also normalised against the pre-application control value. Data are expressed as mean \pm standard error of mean; $n$ refers to the number of biological repetitions.

\section{Results}

\section{Antibody specificity}

In our pilot experiments, we tested several anti- $\mathrm{Na}_{\mathrm{v}} 1.7$ antibodies and immunolabelling procedures on sections cut from rat L4 and L5 DRGs. While all the antibodies provided similar staining pattern, the antibody supplied by Millipore (Supplementary Table 1) and the procedure described above produced the highest signal-to-noise ratio, which we found suitable for quantitative analysis.

In WT mice, a significant proportion of neurons appeared immunopositive in the cytoplasmic compartment as well as in the cytoplasmic membrane (Fig. 1a). In contrast, only a few immunopositive neurons were apparent in sections cut from $\mathrm{Na}_{\mathrm{v}}$ 1.7-cKO mouse DRG (Fig. 1b). The presence of a limited number of Nav1.7immunopositive neurons was expected in Nav1.7-cKO mouse DRG, as neurons that do not express Nav1.8 may express Nav1.7 [14]. No immunostaining was observed in negative controls either when the primary antibody was replaced by normal serum on sections cut from WT mouse DRGs (data not shown) or when it was exhausted with the immunising peptide.

In rat L4-L5 DRGs, a significant proportion of neurons exhibited immunostaining (Fig. 1c). No immunopositive neurons were visible when the primary antibody was replaced by normal serum (data not shown) or exhausted with the immunising peptide (Supplementary Fig. 1a). In the positive control, an already characterised antibody
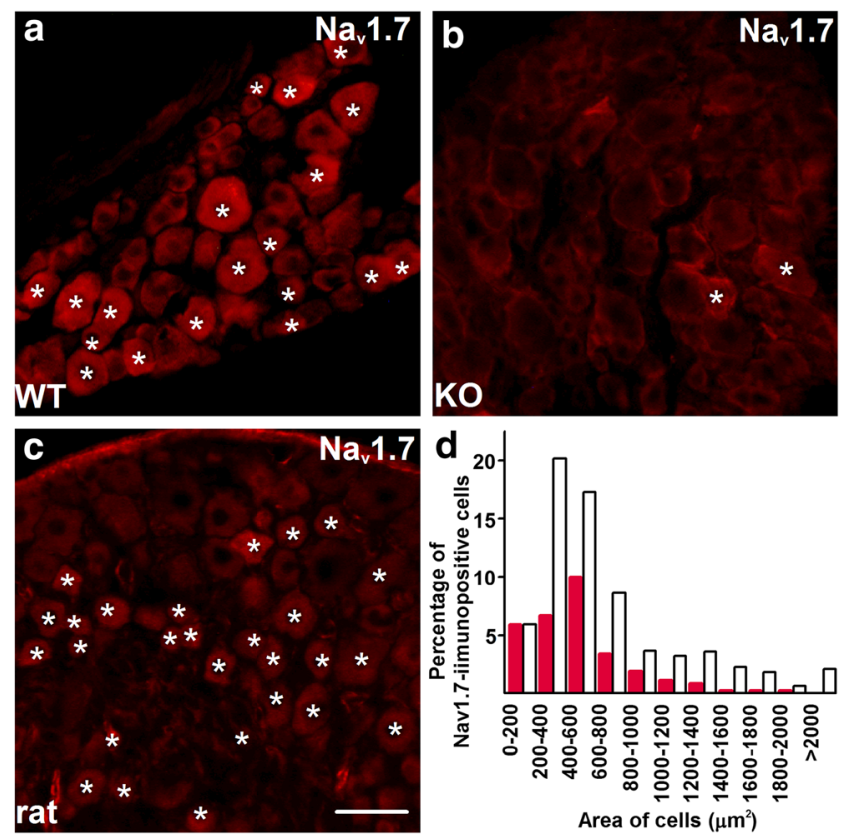

Fig. 1 The anti- $\mathrm{Na}_{\mathrm{v}} 1.7$ antibody specifically identifies a sub-population of primary sensory neurons. a Incubation with the anti- $\mathrm{Na}_{\mathrm{v}} 1.7$ antibody (Millipore, AB5390) results in immunostaining in a group of primary sensory neurons in wild-type (WT) mice. Asterisks indicate immunopositive neurons. b The same anti- $\mathrm{Na}_{\mathrm{v}} 1.7$ antibody produced only faint staining in very few neurons in sections cut from the dorsal root ganglia dissected from mice lacking $\mathrm{Na}_{\mathrm{v}} 1.7$ (KO; asterisks). c The anti- $\mathrm{Na}_{\mathrm{v}} 1.7$ antibody also produces immunostaining in rat primary sensory neurons. Immunopositive cells are indicated by asterisks. $\mathbf{d}$ Cell size distribution of $\mathrm{Na}_{\mathrm{v}} 1.7+$ neurons in the L4 and L5 dorsal root ganglia of naive Sprague-Dawley rats. Note that most of the $\mathrm{Na}_{\mathrm{v}} 1.7+$ neurons are small- and middle-size cells. Empty bars indicate size distribution of all cells whereas red bars indicate the size distribution of neurons exhibiting $\mathrm{Na}_{\mathrm{v}} 1.7$ immunopositivity. Though we have not tested the expression of functional $\mathrm{Na}_{\mathrm{v}} 1.7$, the specificity and selectivity of the antibody suggest the expression of such functional channels. Scale bar $=50 \mu \mathrm{m}$ on each microphotographs (Color figure online) 
(anti-TRPV1 antibody; [15]) showed the characteristic immunopositivity (Supplementary Fig. 1b).

$\mathrm{Na}_{\mathrm{v}} 1.7$ immunopositivity was found in about $25 \%$ of the neurons in naive rat DRGs $(25.69 \pm 6.03 \%, n=4)$. The size distribution confirmed that $\mathrm{Na}_{\mathrm{v}} 1.7$ is expressed predominantly in small- and medium-size neurons (Fig. 1d). The average area of the $\mathrm{Na}_{\mathrm{v}} 1.7$-immunopositive neurons was significantly smaller than that of the $\mathrm{Na}_{\mathrm{v}} 1.7$ immunonegative cells (positive $406.14 \pm 33.64 \mu^{2}$,

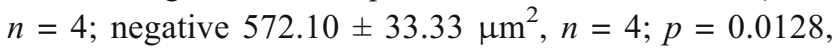
GzLM).

\section{Burn injury upregulates $\mathrm{Na}_{\mathrm{v}} \mathrm{1.7}$ expression in primary sensory neurons}

Western blots of protein extracts from the ipsi- and contralateral DRGs of rats $5 \mathrm{~min}$ and $3 \mathrm{~h}$ after the induction of the burn injury showed the presence of two proteins corresponding to $\mathrm{Na}_{\mathrm{v}} 1.7$, at $\sim 130$ and $\sim 210 \mathrm{kDa}$ molecular masses (Fig. 2a) $[16,17]$. Analysis of the Western blots revealed a significant increase in ipsilateral/contralateral ratio of $\mathrm{Na}_{\mathrm{v}} 1.7$ protein expression at $3 \mathrm{~h}$ post-injury (Fig. 2a, b), but not at the 5 -min post-injury time point (Fig. 2b, Supplementary Fig. 2; $3 \mathrm{~h}$ $1.23 \pm 0.09, n=4 ; 5 \min 0.94 \pm 0.02, n=4, p=0.041$, Student's $t$ test).

Quantification of $\mathrm{Na}_{\mathrm{v}} 1.7$-immunopositive neurons at various time points after the injury confirmed the upregulation of $\mathrm{Na}_{\mathrm{v}} 1.7$ expression in ipsilateral DRG at $3 \mathrm{~h}$ post-injury (naive $25.69 \pm 6.03 \%, 3$ h $55.81 \pm 14.11 \%, n=4$ for each; $p=0.05$, GzLM; Fig. 2c). However, no increase in the proportion of $\mathrm{Na}_{\mathrm{v}} 1.7$-immunopositive DRG neurons in contralateral DRGs at any time point following burn injury (not shown) or at either side following a sham injury was found (naive $25.08 \pm 2.97 \%$, $n=4, p=0.693$; sham ipsilateral $25.72 \pm 9.81 \%, n=4$, $p=0.797$; sham contralateral $27.67 \pm 5.97 \%, n=4$, $p=0.857 ; 5 \min 22.24 \pm 2.57 \%, n=4, p=0.747 ; 30 \mathrm{~min}$ $40.05 \pm 9.55 \%, n=4, p=0.185 ; 1$ h $22.32 \pm 8.28 \%, n=4$, $p=0.753 ; 3$ h $18.96 \pm 9.18 \%, n=4, p=0.532 ;$ GzLM).

\section{p-CREB is a marker for neuronal activation by burn injury}

Phosphorylated CREB (p-CREB) is a common downstream effector of various pathways implicated in regulating transcriptional changes associated with usedependent increase in the activity and excitability (sensitisation) of primary sensory neurons by noxious stimuli [18]. Hence, we assessed whether p-CREB identifies activated primary sensory neurons in our burn injury model.

p-CREB expression exhibited a biphasic increase in primary sensory neurons following burn injury; at 5 min postinjury, p-CREB appeared in the nuclear compartment of a

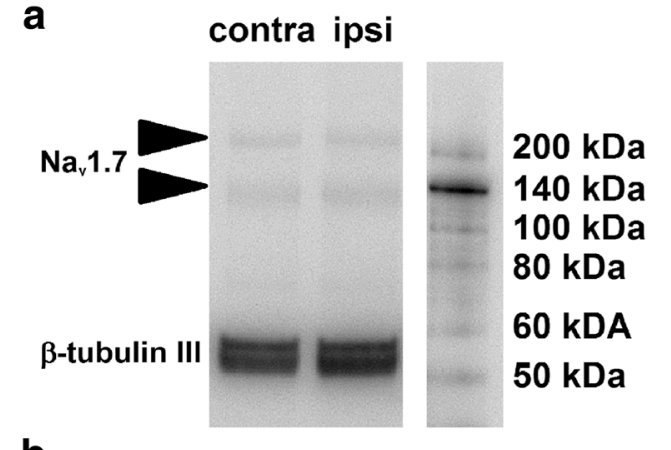

b
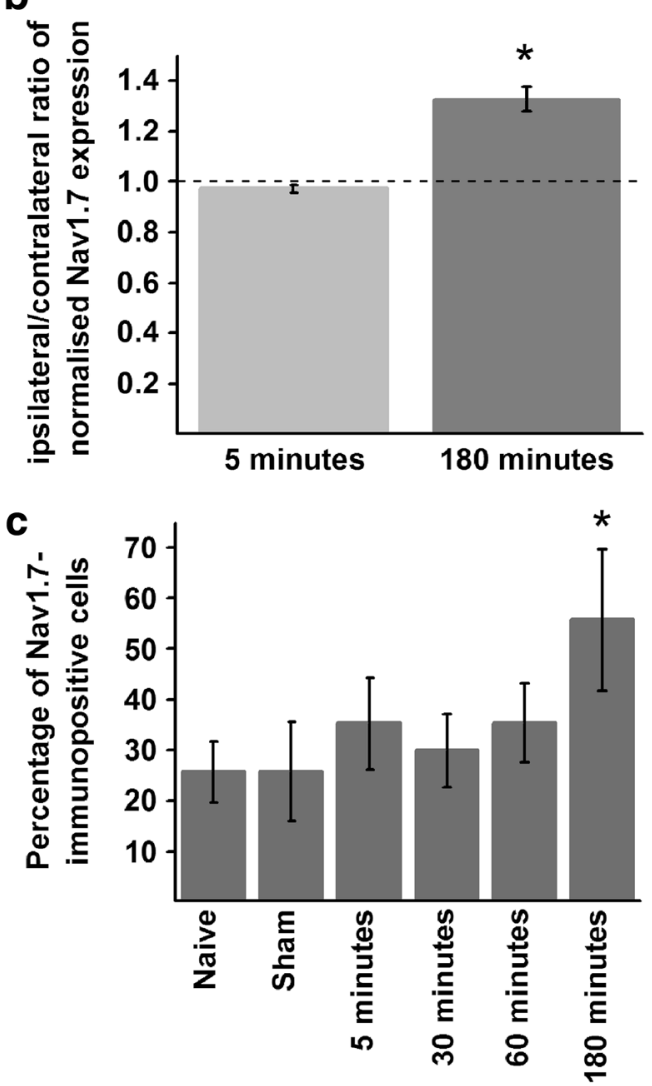

Fig. 2 Burn injury induces upregulation in $\mathrm{Na}_{\mathrm{v}} 1.7$ expression. a A gel image of Western blotting using the anti- $\mathrm{Na}_{\mathrm{v}} 1.7$ and anti- $\beta$ tubulin III antibodies with protein samples isolated from the ipsilateral (ipsi) and contralateral (contra) L4 and L5 dorsal root ganglia of a rat $180 \mathrm{~min}$ after burn injury. Note that both antibodies produced double blots; consistent with previous findings, $\mathrm{Na}_{\mathrm{v}} 1.7$ is expressed at $\sim 135$ and $210 \mathrm{kDa}$ (indicated by an arrowhead), whereas $\beta$ tubulin III expression is between 50 and $60 \mathrm{kDa}$. Both $\mathrm{Na}_{\mathrm{v}} 1.7$ bands were considered for analysis. b Ratios between normalised $\mathrm{Na}_{\mathrm{v}} 1.7$ expression found in the contra- and ipsilateral L4-L5 dorsal root ganglia 5 and $180 \mathrm{~min}$ after burn injury reveal that burn injury induces upregulation in $\mathrm{Na}_{\mathrm{v}} 1.7$ expression. $n=4$. $* p<0.05$. c Quantification of $\mathrm{Na}_{\mathrm{v}} 1.7$ immunostaining in L4-L5 dorsal root ganglia confirms upregulation of $\mathrm{Na}_{\mathrm{v}} 1.7$ expression at $180 \mathrm{~min}$ after burn injury. $n=4$. * $p<0.01$

small- and medium-size neurons $(5 \min 10.98 \pm 3.16 \%$, $n=4$; naive $0.41 \pm 0.41 \%, n=4, p<0.001$; GzLM; Fig. 3a-d). Following a rapid return to baseline expression 
level $(30 \min 2.95 \pm 2.68 \%, n=4, p=0.393 ; 60 \mathrm{~min}$ $3.85 \pm 2.38 \%, n=4, p=0.287$; GzLM), the proportion of p-CREB-expressing neurons was significantly increased again at $3 \mathrm{~h}$ post-injury ( $3 \mathrm{~h} 6.10 \pm 2.41 \%, n=4, p=0.041$ vs naive, $p=0.097$ vs. 5 min, GzLM; Fig. 3d). The majority of neurons exhibiting immunopositivity for p-CREB were small- and medium-size neurons (Fig. 3e; positive
$364.61 \pm 50.78 \mu^{2}, n=4 ;$ negative: $506.51 \pm 26.69 \mu \mathrm{m}^{2}, n=4 ; p=0.001$, GzLM). In addition to primary sensory neurons, $\mathrm{p}$-CREB was also present in the nuclei of some satellite cells 5 min after the burn injury. However, further investigation of this expression was outside the scope of this study; therefore, we did not analyse satellite cell expression of $\mathrm{p}$-CREB any further.
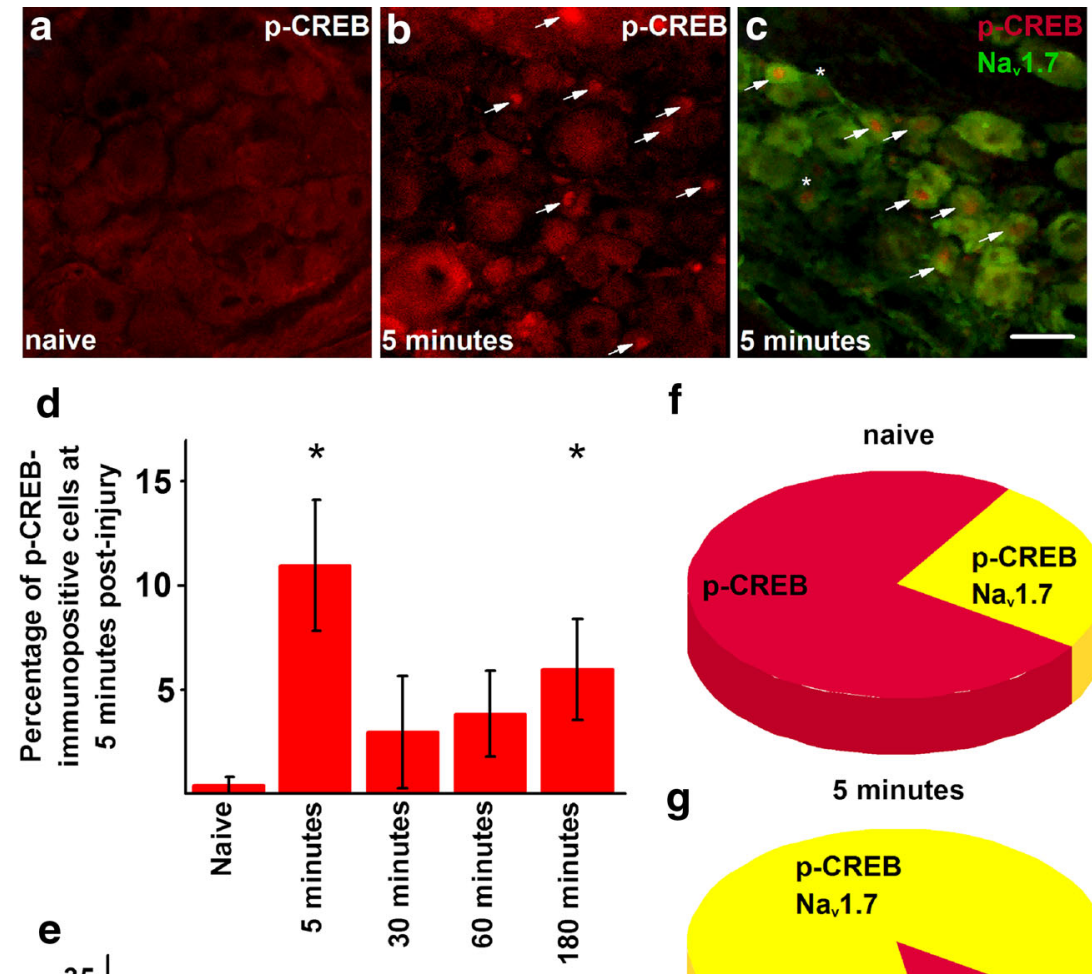

f

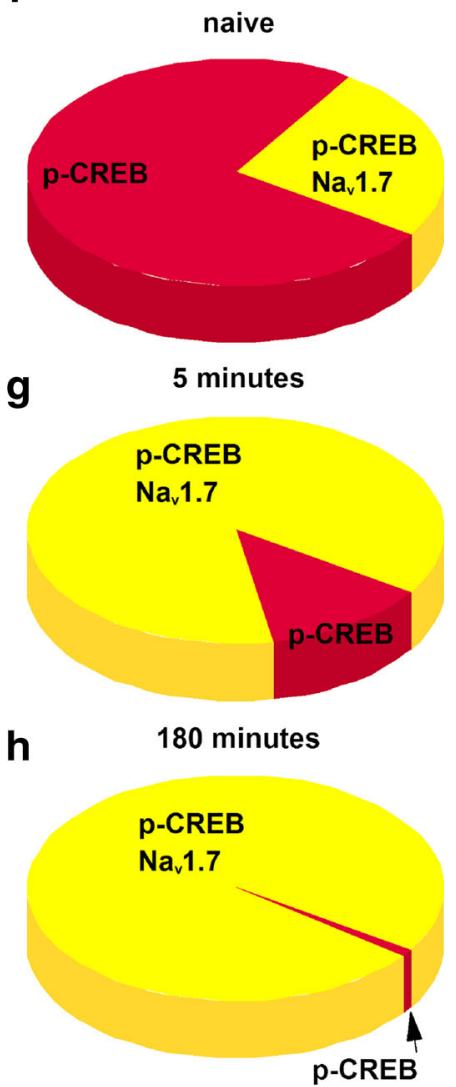

Fig. 3 Burn injury induces upregulation in p-CREB expression in $\mathrm{Na}_{\mathrm{v}}$ 1.7-expressing primary sensory neurons in L4-L5 dorsal root ganglia. a L4-L5 dorsal root ganglia dissected from naive rats contain virtually no neurons which express p-CREB in their nuclei. b Burn injury induces pCREB expression in a significant number of primary sensory neurons in the ipsilateral L4-L5 dorsal root ganglia. Arrows indicate p-CREBimmunopositive nuclei. c Combined immunostaining with the anti$\mathrm{Na}_{\mathrm{v}} 1.7$ (green) and the anti-p-CREB (red) antibodies on sections from the ipsilateral L4-L5 dorsal root ganglia shows that CREB phosphorylation following burn injury occurs predominantly in $\mathrm{Na}_{\mathrm{v}} 1.7$-expressing primary sensory neurons. Arrows show neurons exhibiting double immunopositivity, whereas asterisks indicate neurons with p-CREB

immunopositivity without expressing $\mathrm{Na}_{\mathrm{v}} 1.7$. d Quantification of primary sensory neurons reveals significant upregulation of p-CREB expression at 5 and $180 \mathrm{~min}$ after burn injury in primary sensory neurons in the ipsilateral L4-L5 dorsal root ganglia. Asterisks indicate statistical significance. $n=4$. e Size distribution of neurons exhibiting p-CREB expression in the nucleus (red bars) 5 min after the injury reveals that smalldiameter neurons are activated by burn injury. Empty bars indicate all neurons. $\mathbf{f}-\mathbf{h}$ Pie charts indicating the proportion of primary sensory neurons exhibiting $\mathrm{Na}_{\mathrm{v}} 1.7$ and p-CREB co-expression in the ipsilateral L4 L5 dorsal root ganglia in naive condition, 5 and $180 \mathrm{~min}$ after burn injury, respectively. Scale bar $=50 \mu \mathrm{m}$ on each microphotograph (Color figure online) 


\section{p-CREB is expressed in $\mathrm{Na}_{\mathbf{v}}$ 1.7-expressing neurons}

Double immunostaining revealed that while in the naive rats, about $25 \%$ of the very few cells with p-CREBimmunopositive nuclei exhibited $\mathrm{Na}_{\mathrm{v}} 1.7$ immunopositivity, 5 min after the burn injury, $\sim 90 \%$ of the cells with p-CREB-immunopositive nuclei also exhibited immunopositivity for $\mathrm{Na}_{\mathrm{v}} 1.7(87.5 \pm 7.98 \%, n=4$; Fig. $3 \mathrm{c}, \mathrm{f}, \mathrm{g})$. The co-expression pattern was very similar at $3 \mathrm{~h}$ post-injury ( $p=0.983$; Fig. $3 \mathrm{~h}$ ).

Very few $\mathrm{Na}_{\mathrm{v}} 1.7$-immunopositive neurons showed pCREB immunopositivity in naive animals $(13.3 \pm 3.33 \%$, $n=4)$. The co-expression pattern increased to around $80 \%$ $5 \mathrm{~min}$ after the burn injury $(77.58 \pm 10.16 \%, n=4)$, and this proportion remained similar at $3 \mathrm{~h}$ post-injury $(63.42 \pm 10.31 \%, n=4 ; p=0.758)$.

Together, these data support recent reports on the pivotal role of $\mathrm{Na}_{\mathrm{v}} 1.7$ in the development of burn injury-associated pain [4]. Those reports also showed that $\mathrm{Na}_{\mathrm{v}} 1.7$ is particularly important in the development of burn injury-associated heat hyperalgesia [4]. We have shown most recently that burn injury induces a rapid and sustained upregulation of $\mathrm{p}-\mathrm{S} 10 \mathrm{H} 3$ in a sub-population of spinal dorsal horn neurons [12]. Our findings also indicate that $\mathrm{p}-\mathrm{S} 10 \mathrm{H} 3$ can be used as a marker for nociceptive activation of spinal cord neurons involved in the development of inflammatory heat hyperalgesia [12]. Therefore, next, we assessed the effect of blocking $\mathrm{Na}_{\mathrm{v}} 1.7$ on $\mathrm{p}-\mathrm{S} 10 \mathrm{H} 3$ expression in the spinal dorsal horn.

\section{$\mathrm{Na}_{\mathrm{v}} 1.7$ blockade partially reduces burn injury-induced nociceptive activation in spinal cord neurons}

Burn injury induced a significant increase in the number of neurons with nuclei immunopositive for $\mathrm{p}-\mathrm{S} 10 \mathrm{H} 3$ in the ipsilateral spinal dorsal horn at $60 \mathrm{~min}$ post-injury $(60 \mathrm{~min}$ $30.00 \pm 1.73, n=3$; control: $2.33 \pm 0.88, n=3 ; p<0.001$, GzLM; Fig. 4a, b, g). Neurons exhibiting nuclei with pS10H3 immunopositivity were distributed among $\mathrm{Na}_{\mathrm{v}} 1.7$ immunopositive fibres (Supplementary Fig. 3). Intraperitoneal injection of ProTxII 15 min before the injury significantly reduced the number of $\mathrm{pS} 10 \mathrm{H} 3$-positive nuclei in the ipsilateral spinal dorsal horn (Fig. 4a-c, g; ProTxII-before $12.33 \pm 1.45, n=3, p<0.001$, GzLM). ProTxII, injected $15 \mathrm{~min}$ after the injury, also significantly reduced the number of neurons exhibiting p-S10H3 expression in the ipsilateral spinal dorsal horn (Fig. 4a, b, d, g; ProTxII-after: $11.33 \pm 1.20, n=3, p<0.001$, GzLM). There was no difference between the reductions produced by protoxin injection before or after the injury ( $p=0.491$, GzLM; Fig. $4 \mathrm{~g}$ ).

Morphine injection $15 \mathrm{~min}$ before the injury completely prevented the upregulation of $\mathrm{p}-\mathrm{S} 10 \mathrm{H} 3$ expression by burn injury (morphine-before $1.66 \pm 0.88, n=3, p=0.646$, GzLM; Fig. 4a, b, e, g). Morphine, injected 15 min after the induction of the burn injury, significantly reduced the number of neurons exhibiting p-S10H3-immunopositive nuclei (morphine-after $11.33 \pm 1.20, n=3, p<0.001$, GzLM; Fig. 4a, b, f, $\mathrm{g})$. The number of activated neurons found in the morphineafter group was not significantly different from that found in naive animals. Both ProTxII and morphine had similar effects on the expression of phosphorylated ERK (p-ERK) 1/2 in the spinal cord (Supplementary Fig. 4).

\section{ProTxII reduces sEPSC frequency following burn injury}

To confirm that ProTxII reduces spinal nociceptive processing in burn injury, we also assessed the effect of ProTxII on sEPSCs in the spinal superficial dorsal horn neurons. sEPSC frequency in sham-operated animals was $0.8 \pm 0.2 \mathrm{~Hz}(n=9)$, and ProTxII $(10 \mathrm{nM})$ did not change that $(99.7 \pm 8.7 \%$ of the control value; Fig. 5a, b). sEPSC amplitudes in naive slices were $-14.7 \pm 2.0 \mathrm{pA}$ before and $-15.1 \pm 2.2 \mathrm{pA}$ after the ProTxII. All the tested neurons responded to capsaicin $(200 \mathrm{nM} ; 25.6 \pm 5.7 \mathrm{~Hz}, n=8 ; p=0.003)$.

sEPSC frequency exhibited a robust and significant increase following burn injury $(3.1 \pm 0.6 \mathrm{~Hz}$; Fig. $5 \mathrm{a}, \mathrm{b}$, $p=0.002)$. ProTxII significantly decreased the SESPC frequency to $2.1 \pm 0.5 \mathrm{~Hz}(66.2 \pm 8.1 \%$ of the control value; Fig. 5a, b). The average sEPSC amplitude was $-17.8 \pm 3.4 \mathrm{pA}$, and ProTxII did not change that $(-17.1 \pm 3.6 \mathrm{pA})$. All neurons responded to capsaicin $(31.5 \pm 7.1 \mathrm{~Hz} ; n=10 ; p=0.003)$. The capsaicin response was not different in the sham and injured groups.

\section{Discussion}

Similar to previous reports, we found that a significant proportion of primary sensory neurons express $\mathrm{Na}_{\mathrm{v}} 1.7[5,17]$. While we did not test whether $\mathrm{Na}_{\mathrm{v}} 1.7$ is functional in the $\mathrm{Na}_{\mathrm{v}} 1.7$-expressing primary sensory neurons, previous findings that a significant proportion of primary sensory neurons do express such currents $[4,5,14,17,19]$ indicate that at least a proportion of the $\mathrm{Na}_{\mathrm{v}} 1.7$-immunopositive neurons express functional $\mathrm{Na}_{\mathrm{v}} 1.7$ channels.

Both Western blotting and immunostaining revealed that $\mathrm{Na}_{\mathrm{v}} 1.7$ expression is increased in DRGs by $3 \mathrm{~h}$ post-injury. Similar upregulation has been reported in other peripheral inflammatory models $[20,21]$. Increased density of $\mathrm{Na}_{\mathrm{v}} 1.7$ mediated currents in primary sensory neurons following burn injury was also reported recently [4]. The increased $\mathrm{Na}_{\mathrm{v}} 1.7$ expression and the increased density of $\mathrm{Na}_{\mathrm{v}} 1.7$-mediated currents, $3 \mathrm{~h}$ and 2 days after the injury, respectively, support the view that $\mathrm{Na}_{\mathrm{v}} 1.7$ significantly contributes in enhancing nociceptive signalling of primary sensory neurons during the entire course of burn injury [4]. 

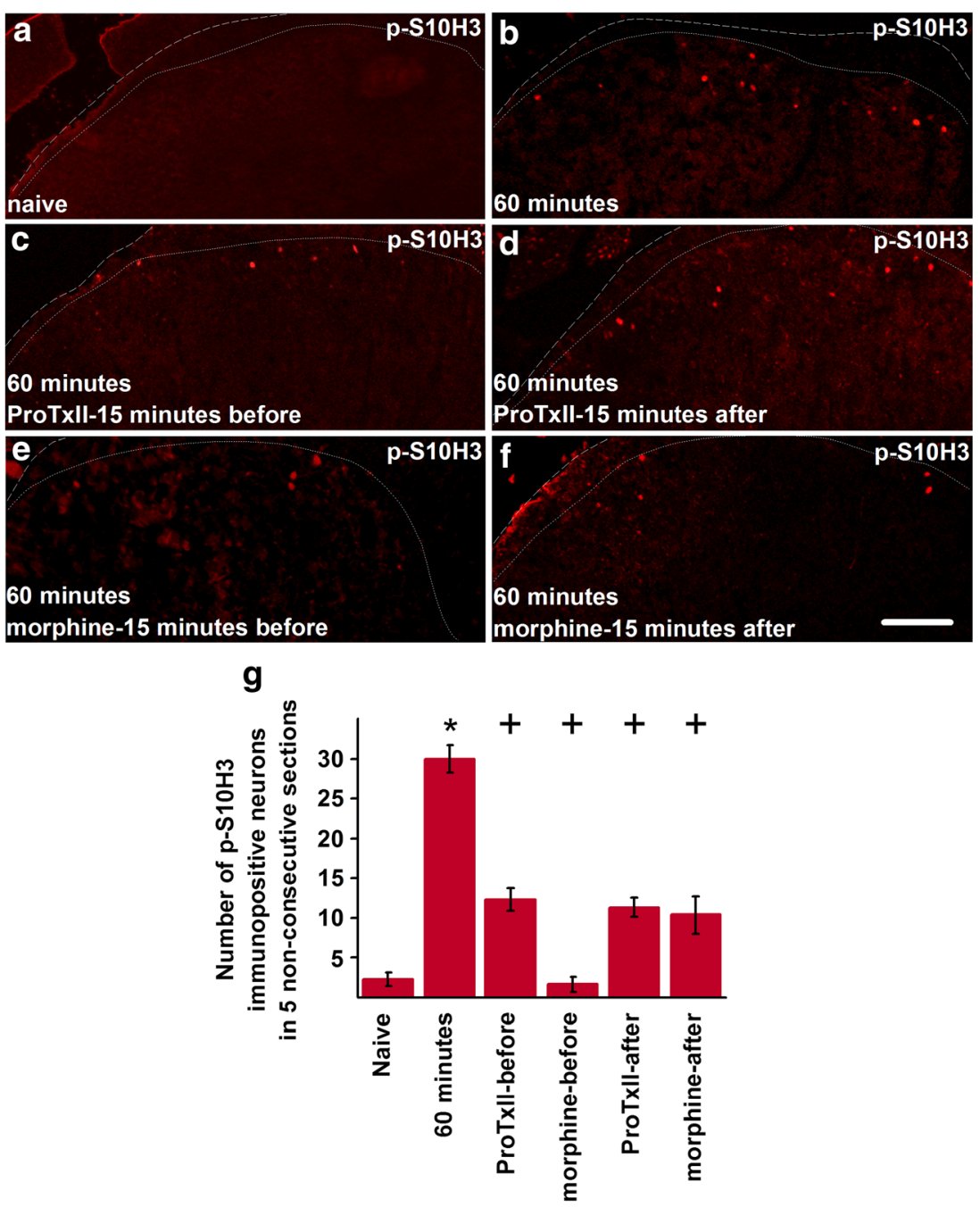

Fig. 4 Intraperitoneal injection of protoxin II or morphine reduces burn injury-induced upregulation of $\mathrm{p}-\mathrm{S} 10 \mathrm{H} 3$ expression in the ipsilateral spinal dorsal horn. a-f p-S10H3 expression in the ipsilateral spinal dorsal horn in naive condition (a), 60 min after burn injury (b), with the injection of protoxin II $15 \mathrm{~min}$ before (c) or $15 \mathrm{~min}$ after (d) the injury and with the injection of morphine $15 \mathrm{~min}$ before (e) or $15 \mathrm{~min}$ after (f) the injury. Dashed lines indicate the border of the spinal cord, whereas dotted lines indicate the white-grey matter border. Note that burn injury induces upregulation in the expression of $\mathrm{p}-\mathrm{S} 10 \mathrm{H} 3$, whereas either protoxin II or

Burn injury induced a biphasic upregulation in the expression of $\mathrm{p}$-CREB, a marker for neurons activated by various painful peripheral pathologies, including inflammation of various origins in primary sensory neurons $[18,22]$. The increase at $5 \mathrm{~min}$ could be due to the activation of neurons by the excessive heat and/or molecules released from the degenerated cells. The increase at $180 \mathrm{~min}$ could be due to the activation of neurons by inflammatory mediators [1]. Importantly, we found a high degree of co-expression between $\mathrm{Na}_{\mathrm{v}} 1.7$ and p-CREB after burn injury indicating that $\mathrm{Na}_{\mathrm{v}} 1.7$ expressing neurons are activated by this injury.

We analysed p-ERK $1 / 2$ and $\mathrm{p}-\mathrm{S} 10 \mathrm{H} 3$ expressions to find the effect of morphine and ProTxII on spinal nociceptive morphine reduces that upregulation irrespective of whether the drug is given before or after the injury. $g$ Quantification of neurons exhibiting $\mathrm{p}$ $\mathrm{S} 10 \mathrm{H} 3$ expression in various conditions. Asterisk indicates significant difference in the number of $\mathrm{p}-\mathrm{S} 10 \mathrm{H} 3$-expressing nuclei between naive condition and $60 \mathrm{~min}$ after burn injury, whereas plus signs indicate significant difference in the number of $\mathrm{p}-\mathrm{S} 10 \mathrm{H} 3$-expressing nuclei between $60 \mathrm{~min}$ after burn injury and various treatments. Scale bar $=100 \mu \mathrm{m}$ on each image

processing. While p-ERK1/2 is well-established, p-S10H3 is a novel marker for nociceptive activation of spinal dorsal horn neurons [11, 12, 23]. As confirmed in the present study, burn injury induces sustained upregulation in both p-ERK1/2 and p-S10H3 expressions in the spinal dorsal horn [11, 12].

Both morphine and ProTxII, which respectively activates the $\mu$-opioid receptors (MOR; [24]) and inhibits $\mathrm{Na}_{\mathrm{v}} 1.7$ [10], significantly reduced the burn injury-induced upregulation of both $\mathrm{p}$-ERK1/2 and $\mathrm{p}-\mathrm{S} 10 \mathrm{H} 3$ expressions. While the finding that morphine reduces spinal nociceptive processing is in full agreement with a large body of previous findings $[25,26]$, the effect of ProTxII appears to be in contrast to previous reports that intravenous or intrathecal ProTxII injection does not 
a

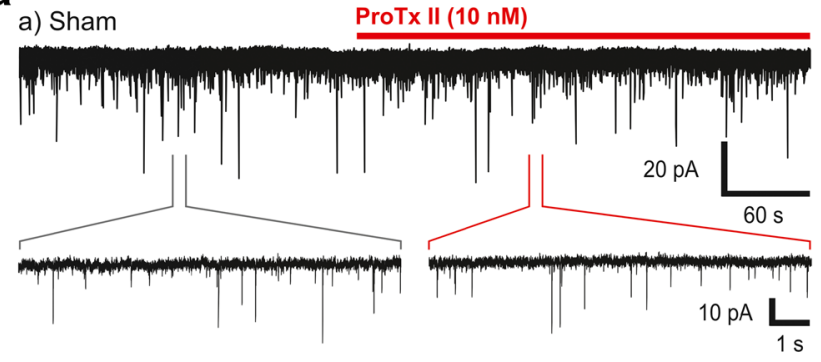

b) Burn injury $\quad$ ProTx II (10 nM)

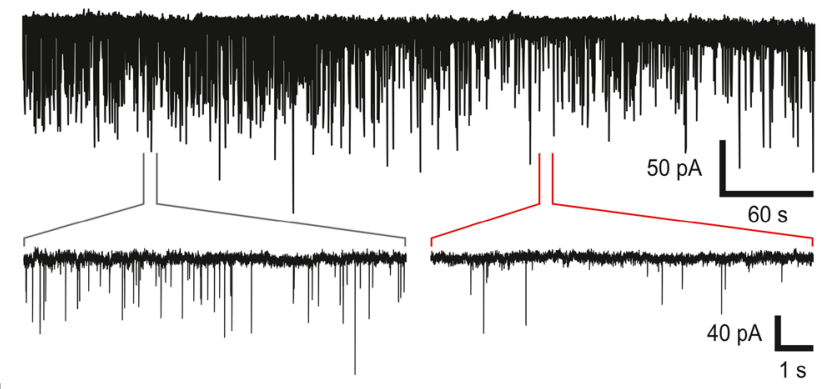

b

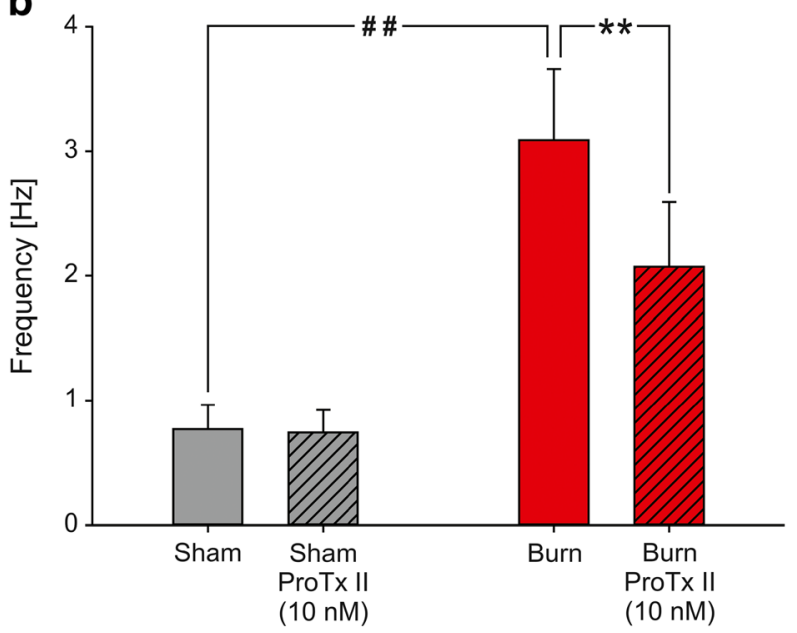

Fig. 5 ProTxII significantly reduces sEPSC frequency following burn injury. The effect of ProTxII sEPSC frequency recorded from the spinal superficial dorsal horn neurons. In the slices with the sham treatment $(n=9)$, the basal sEPSC frequency was low and ProTxII $(10 \mathrm{nM})$ did not produce any change (a, $\mathbf{b}$, sham). Neurons in slices prepared after the burn injury $(n=10)$ exhibited a robust increase in SEPSCs $(\mathbf{a}$, burn injury), and the application of ProTxII induced a significant decrease of the sEPSC frequency $(\mathbf{a}, \mathbf{b}, * * p=0.006)$. The basal sEPSC frequency in the sham group and the burn injury group was significantly different (b, $\# \# p=0.002)$

reduce pain-related behaviour [10]. Although due to animal welfare considerations, we did not assess pain-related behaviour, the similar magnitude of inhibitory effects by morphine and ProTxII administration following the injury suggests that similar to morphine [27], ProTxII is also highly likely to produce an analgesic effect.

The lack of effect by ProTxII on pain-related behaviour was attributed to the inability of the toxin to access $\mathrm{Na}_{\mathrm{v}} 1.7$ in intact peripheral nerves and to pass the blood-brain barrier $[10,28]$. However, a recent finding has demonstrated that
ProTxII can access $\mathrm{Na}_{\mathrm{v}} 1.7$ in the spinal cord following intrathecal delivery as well as the peripheral nerve after perineural application [29]. Our data suggest that in addition to those, ProTxII may also reach $\mathrm{Na}_{\mathrm{v}} 1.7$ following intraperitoneal injection. While we did not assess the site of action, based on previous findings, we propose that the ProTxII-produced inhibitory effect on spinal nociceptive processing could be due to ProTxII-induced inhibition of $\mathrm{Na}_{\mathrm{v}} 1.7$ expressed on free nerve endings at the injured tissues as well as the central terminals of Nav1.7-expressing primary sensory neurons.

The significantly larger effect of morphine than of ProTxII on the upregulation of both $\mathrm{p}-\mathrm{S} 10 \mathrm{H} 3$ and $\mathrm{p}$ ERK1/2 when applied before the injury could be due to the differing respective access to MOR and $\mathrm{Na}_{\mathrm{v}} 1.7$ of morphine and ProTxII in various parts of primary sensory neurons in naive conditions $[25,26]$.

The effect of morphine or ProTxII applied 15 min after the injury that models the time course of burn-injured patients receiving analgesics for the first time shows that both drugs are able to induce a significant downregulation in the expression of both markers, hence reducing spinal nociceptive processing. Interestingly, ProTxII produces a greater downregulation in $\mathrm{p}-\mathrm{S} 10 \mathrm{H} 3$ than $\mathrm{p}-\mathrm{ERK} 1 / 2$ expression, which could be due to both $\mathrm{Na}_{\mathrm{v}} 1.7$ and p$\mathrm{S} 10 \mathrm{H} 3$ being involved in the development of heat hypersensitivity $[4,7,8,12]$, whereas p-ERK $1 / 2$ is involved in the development of both thermal and mechanical hypersensitivities [23]. Nevertheless, the downregulation of pERK1/2 and p-S10H3 by morphine or ProTxII $15 \mathrm{~min}$ after the injury indicates that ongoing activity of MORand/or $\mathrm{Na}_{\mathrm{v}} 1.7$-expressing primary sensory neurons is needed for the nociceptive activation of the spinal dorsal horn neurons in burn injury.

Our electrophysiological recordings confirm the significant role of $\mathrm{Na}_{\mathrm{v}} 1.7$ in spinal nociceptive processing following burn injury. Burn injury significantly increased sEPSC frequency which was significantly reduced by ProTxII. The differential effect of ProTxII in naive slices and slices prepared after burn injury could be due to $\mathrm{Na}_{\mathrm{v}} 1.7$ playing a minor role, whereas it gains a much more prominent role in generating spontaneous activity of nociceptive primary sensory neurons in naive condition and after burn injury, respectively. Alternatively, ProTxII, due to neuroinflammatory processes in the spinal cord, may have access to $\mathrm{Na}_{\mathrm{v}} 1.7$ on the central terminals of the primary sensory neuron after burn injury.

Morphine or other opioids used currently to control pain in burn-injured patients induce a series of undesirable effects $[30,31]$. Based on the similar effects of morphine and ProTxII on $p$-ERK1/2 and p-S10H3 expressions by the spinal dorsal horn neurons and the role of $\mathrm{p}$-ERK $1 / 2$ and $\mathrm{p}$-S10H3 in the development of persistent pain associated with peripheral pathologies [11, 12, 32, 33], we propose that blocking $\mathrm{Na}_{\mathrm{v}} 1.7$ could reduce pain, particularly heat hyperalgesia $[4,7,8]$, in 
burn injury with a potency equivalent to that produced by morphine.

Previous attempts to recapitulate the profound analgesic phenotype of $\mathrm{Na}_{\mathrm{v}} 1.7^{-/-}$mice or loss of function human mutations $[5,19]$ by pharmacological agents produced disappointing results [3]. However, a recent report has shown that a ProTxII-based designer peptide acting on $\mathrm{Na}_{\mathrm{v}} 1.7$ is able to reproduce the analgesic phenotype observed in mice lacking $\mathrm{Na}_{\mathrm{v}} 1.7^{-/-}$or humans having a loss of function $\mathrm{Na}_{\mathrm{v}} 1.7$ mutations [29]. Therefore, based on the expression pattern of $\mathrm{Na}_{\mathrm{v}} 1.7[5,14,17,19]$, it is likely that blocking $\mathrm{Na}_{\mathrm{v}} 1.7$, particularly in a cell-specific manner, could produce a significant analgesic effect with significantly less undesirable effects than opioids.

Funding information This work was supported by the Chelsea and Westminster Health Charity, KTIA_NAP_13-2-2014-0005, and GACR 15-11138S, MSMT LQ1604, LḦ15279, CZ.1.05/1.1.00/02.0109, GAUK138215 and RVO 67985823 grants.

Compliance with ethical standards We obeyed the UK Animals (Scientific Procedures) Act 1986, the guidelines of the revised National Institutes of Health Guide for the Care and Use of Laboratory Animals, Directive 2010/63/EU of the European Parliament and of the Council on the Protection of Animals Used for Scientific Purposes and the Committee for Research and Ethical Issues of IASP published in Pain, 16 (1983) 109-110 and adhered to Good Laboratory Practice and ARRIVE guidelines. Procedures were approved by veterinary services at all relevant institutions.

Conflict of interest The authors declare that they have no conflict of interest.

Open Access This article is distributed under the terms of the Creative Commons Attribution 4.0 International License (http:// creativecommons.org/licenses/by/4.0/), which permits unrestricted use, distribution, and reproduction in any medium, provided you give appropriate credit to the original author(s) and the source, provide a link to the Creative Commons license, and indicate if changes were made.

\section{References}

1. Laycock H, Valente J, Bantel C, Nagy I (2013) Peripheral mechanisms of burn injury-associated pain. Eur J Pharmacol 716:169-178

2. Julius D, Basbaum AI (2001) Molecular mechanisms of nociception. Nature 413:203-210

3. Eijkelkamp N, Linley JE, Baker MD, Minett MS, Cregg R, Werdehausen R, Rugiero F, Wood JN (2012) Neurological perspectives on voltage-gated sodium channels. Brain 135:2585-2612

4. Shields SD, Cheng X, Uceyler N, Sommer C, Dib-Hajj SD, Waxman SG (2012) Sodium channel $\mathrm{Na}(v) 1.7$ is essential for lowering heat pain threshold after burn injury. J Neurosci 32: 10819-10832

5. Nassar MA, Stirling LC, Forlani G, Baker MD, Matthews EA, Dickenson AH, Wood JN (2004) Nociceptor-specific gene deletion reveals a major role for Nav1.7 (PN1) in acute and inflammatory pain. Proc Natl Acad Sci U S A 101:12706-12711

6. Hille B (1972) The permeability of the sodium channel to metal cations in myelinated nerve. J Gen Physiol 59:637-658
7. Cai W, Cao J, Ren X, Qiao L, Chen X, Li M, Zang W (2016) shRNA mediated knockdown of Nav1.7 in rat dorsal root ganglion attenuates pain following burn injury. BMC Anesthesiol 16:59

8. Salas MM, McIntyre MK, Petz LN, Korz W, Wong D, Clifford JL (2015) Tetrodotoxin suppresses thermal hyperalgesia and mechanical allodynia in a rat full thickness thermal injury pain model. Neurosci Lett 607:108-113

9. Middleton RE, Warren VA, Kraus RL, Hwang JC, Liu CJ, Dai G, Brochu RM, Kohler MG, Gao YD, Garsky VM et al (2002) Two tarantula peptides inhibit activation of multiple sodium channels. Biochemistry 41:14734-14747

10. Schmalhofer WA, Calhoun J, Burrows R, Bailey T, Kohler MG, Weinglass AB, Kaczorowski GJ, Garcia ML, Koltzenburg M, Priest BT (2008) ProTx-II, a selective inhibitor of NaV1.7 sodium channels, blocks action potential propagation in nociceptors. Mol Pharmacol 74:1476-1484

11. White JP, Ko CW, Fidalgo AR, Cibelli M, Paule CC, Anderson PJ, Cruz C, Gomba S, Matesz K, Veress G et al (2011) Severe burn injury induces a characteristic activation of extracellular signalregulated kinase 1/2 in spinal dorsal horn neurons. Eur J Pain 15: 683-690

12. Torres-Perez JV, Santha P, Varga A, Szucs P, Sousa-Valente J, Gaal B, Sivado M, Andreou AP, Beattie S, Nagy B et al (2017) Phosphorylated histone 3 at serine 10 identifies activated spinal neurons and contributes to the development of tissue injuryassociated pain. Sci Rep 7:41221. https://doi.org/10.1038/ srep41221

13. Spicarova D, Palecek J (2009) The role of the TRPV1 endogenous agonist $\mathrm{N}$-oleoyldopamine in modulation of nociceptive signaling at the spinal cord level. J Neurophysiol 102:234-243

14. Minett MS, Nassar MA, Clark AK, Passmore G, Dickenson AH, Wang F, Malcangio M, Wood JN (2012) Distinct Nav1.7-dependent pain sensations require different sets of sensory and sympathetic neurons. Nat Commun 3:791

15. Caterina MJ, Schumacher MA, Tominaga M, Rosen TA, Levine JD, Julius D (1997) The capsaicin receptor: a heat-activated ion channel in the pain pathway. Nature 389:816-824

16. Laedermann CJ, Syam N, Pertin M, Decosterd I, Abriel H (2013) Beta1- and beta3-voltage-gated sodium channel subunits modulate cell surface expression and glycosylation of Nav1.7 in HEK293 cells. Front Cell Neurosci 7:137

17. Toledo-Aral JJ, Moss BL, He ZJ, Koszowski AG, Whisenand T, Levinson SR, Wolf JJ, Silos-Santiago I, Halegoua S, Mandel G (1997) Identification of PN1, a predominant voltage-dependent sodium channel expressed principally in peripheral neurons. Proc Natl Acad Sci U S A 94:1527-1532

18. Qiao LY, Vizzard MA (2004) Up-regulation of phosphorylated CREB but not c-Jun in bladder afferent neurons in dorsal root ganglia after cystitis. J Comp Neurol 469:262-274

19. Dib-Hajj SD, Cummins TR, Black JA, Waxman SG (2007) From genes to pain: Na v 1.7 and human pain disorders. Trends Neurosci 30:555-563

20. Gould HJ 3rd, England JD, Liu ZP, Levinson SR (1998) Rapid sodium channel augmentation in response to inflammation induced by complete Freund's adjuvant. Brain Res 802:69-74

21. Black JA, Liu S, Tanaka M, Cummins TR, Waxman SG (2004) Changes in the expression of tetrodotoxin-sensitive sodium channels within dorsal root ganglia neurons in inflammatory pain. Pain 108:237-247

22. Li MY, Lai FJ, Hsu LJ, Lo CP, Cheng CL, Lin SR, Lee MH, Chang JY, Subhan D, Tsai MS et al (2009) Dramatic co-activation of WWOX/WOX1 with CREB and NF-kappaB in delayed loss of small dorsal root ganglion neurons upon sciatic nerve transection in rats. PLoS One 4:e7820. https://doi.org/10.1371/journal.pone. 0007820 
23. Ji RR, Befort K, Brenner GJ, Woolf CJ (2002) ERK MAP kinase activation in superficial spinal cord neurons induces prodynorphin and NK-1 upregulation and contributes to persistent inflammatory pain hypersensitivity. J Neurosci 22:478-485

24. Wood PL (1988) The significance of multiple CNS opioid receptor types: a review of critical considerations relating to technical details and anatomy in the study of central opioid actions. Peptides 9(Suppl 1):49-55

25. Yaksh TL (1981) Spinal opiate analgesia: characteristics and principles of action. Pain 11:293-346

26. Liang DY, Sun Y, Shi XY, Sahbaie P, Clark JD (2014) Epigenetic regulation of spinal cord gene expression controls opioid-induced hyperalgesia. Mol Pain 10:59

27. Wang S, Lim G, Yang L, Zeng Q, Sung B, Jeevendra Martyn JA, Mao J (2005) A rat model of unilateral hindpaw burn injury: slowly developing rightwards shift of the morphine dose-response curve. Pain 116:87-95

28. Hackel D, Krug SM, Sauer RS, Mousa SA, Bocker A, Pflucke D, Wrede EJ, Kistner K, Hoffmann T, Niedermirtl B et al (2012)
Transient opening of the perineurial barrier for analgesic drug delivery. Proc Natl Acad Sci U S A 109:E2018-E2027

29. Flinspach M, Xu Q, Piekarz AD, Fellows R, Hagan R, Gibbs A, Liu Y, Neff RA, Freedman J, Eckert WA et al (2017) Insensitivity to pain induced by a potent selective closed-state Nav1.7 inhibitor. Sci Rep 7:39662. https://doi.org/10.1038/srep39662

30. Carrougher GJ, Ptacek JT, Sharar SR, Wiechman S, Honari S, Patterson DR, Heimbach DM (2003) Comparison of patient satisfaction and self-reports of pain in adult burn-injured patients. J Burn Care Rehabil 24:1-8

31. Benyamin R, Trescot AM, Datta S, Buenaventura R, Adlaka R, Sehgal N, Glaser SE, Vallejo R (2008) Opioid complications and side effects. Pain Physician 11:S105-S120

32. Ji RR, Baba H, Brenner GJ, Woolf CJ (1999) Nociceptive-specific activation of ERK in spinal neurons contributes to pain hypersensitivity. Nat Neurosci 2:1114-1119

33. White JP, Cibelli M, Fidalgo AR, Nagy I (2011) Extracellular signal-regulated kinases in pain of peripheral origin. Eur $\mathrm{J}$ Pharmacol 650:8-17 